\title{
La frontera y la línea fronteriza: puntos de vista mexicanos y americanos de la frontera méxico-americana
}

\author{
Richard Griswold del Castillo \\ Universidad Estatal de San Diego
}

\begin{abstract}
Resumen
A lo largo de los siglos, los mexicanos y estadounidenses han desarrollado conceptos diferentes con relación a su región fronteriza común. Muchas de las diferencias en perspectivas nacionales, son el resultado de sus culturas históricas y definiciones de interés propio. El propósito de este escrito es delinear en forma general el origen de perspectivas mexicanas y estadounidenses de la región geográfica que ha sido llamada la frontera MéxicoEstados Unidos. Finalmente, el valor real de la historia consiste en que nos permite evaluar ideas y culturas en sus patrones que tienen raíces profundas en nuestra experiencia colectiva pasada. Históricamente, para mexicanos y americanos, la frontera ha sido un lugar de conflicto y mezcla cultural. No es ni ha sido nunca una zona homogénea, ni regional, ni internacionalmente. Es necesario que los que planean comprendan los puntos de convergencia y divergencia en actitudes mexicanas y anglo-mexicanas hacia la frontera común.
\end{abstract}

Palabras clave: sociedad fronteriza, indígenas norteños, suroeste americano, "la línea", migraciones masivas.

\begin{abstract}
Along many centuries, Mexican and American have developed different concepts regarding their common border region. Many differences on domestic perspectives are the result of their historic cultures and their own interest's definitions. The purpose of this document is to offer a general outline of the origins of Mexican and American perspectives of the geographical region named "the Mexican-United States border". Finally, the true value of history lies on the fact that it allows us to appraise the patterns of ideas and cultures that share their deep roots in our past collective experience. Historically, for Mexicans and Americans, the border has been the place of conflict and cultural mix. Regionally and internationally, it never has been a homogeneous zone. It is necessary that those who make plans understand the convergent and divergent points of Mexican and Mexican-American attitudes toward this common border.
\end{abstract}

Keywords: border society, Northern Indians, American Southwest, the "line", massive migrations. 


\title{
LA FRONTERA Y LA LINEA FRONTERIZA: PUNTOS DE VISTA MEXICANOS Y AMERICANOS SOBRE LA FRONTERA MEXICO-AMERICANA
}

\author{
Por \\ Richard Griswold del Castillo \\ Profesor de la Universidad Estatal de San Diego
}

A lo largo de los siglos, los mexicanos y estadounidenses han desarrollado conceptos diferentes con relación a su región fronteriza común. Muchas de las diferencias en perspectivas nacionales, son el resultado de sus culturas históricas respectivas y defịniciones de interés propio.

El propósito de este escrito es delinear, en una forma general, el origen de perspectivas mexicanas y estadounidenses de la región geográfica que ha sido llamada la frontera méxico-americana. ${ }^{1}$ Ultimamente el valor real de la historia consiste en que nos permite evaluar ideas y culturas en sus patrones que tienen raíces profundas en nuestra experiencia colectiva pasada. La publicidad de los eventos y ediciones contemporáneas muchas veces distorsiona la importancia que a largo plazo tienen las pólizas y las actitudes repetidamente. Si se va a decidir sobre pólizas para el futuro, de éxito a largo plazo, es necesario que los que planean comprendan los puntos de convergencia y divergencia en actitudes mexicanas y anglomexicanas hacia la frontera común.

\section{Puntos de vista mexicanos}

Aún antes de que los españoles llegaran a Norteamérica, las naciones civilizadas del centro de México consideraban a la región norte como un lugar lleno de peligros. Los toltecas construyeron fuertes militares en el norte para protegerse de invasiones de tribus hostiles. Supuestamente, era de esta región que los aztecas descendieron al centro de México como tribus nómadas de ruda magnificiencia. Los aztecas tenían poca ilusión acerca de sus lugares de origen, Aztlán. Para ellos era ". . . un lugar de misterio, dolor, sufrimiento, fatiga, pobreza, tormento. Es un lugar de rocas secas, de fracasos, un lugar de lamentaciones: un lugar de muerte por sed, un lugar de hambre: es un lugar de mucha hambre, de mucha muerte. Es hacia el Norte". $^{2}$ Los españoles llamaban a esta región "La Gran Chichimeca" o tierra de indios bárbaros. Al principio tenían muchas esperanzas de que encontrarían "un otro México" otro México-Tenochtitlan de igualdad en fabulosas

\footnotetext{
${ }^{1}$ Miguel León Portilla. "El norteño, variedad de culturas mexicanas. Un acercamiento etnicohistórico", en La Sociedad Plural en el Suroeste, editado por Edward M. Spicer y Raymand Thompson (Albuquerque: Universidad de Nuevo México 1972), pp, 77-109.

2De P. Armillas. La Frontera Arida de Civilización Mexicana. Transacciones de la Academia de Ciencia de Nueva York, 2da. serie, XXXI, No. 6 (Junio 1969).
} 
riquezas. Pero esta ilusión de grandes riquezas y aventuras exóticas pronto se evaporó con las infructuosas exploraciones de Francisco de Coronado y Juan de Oñate. La frontera norte se volvió una región medio olvidada, y administrativamente descuidada por el imperio español hasta que poderes extranjeros comenzaron a instalarse en territorios adyacentes. En cierto modo, la región norte siempre había sido una frontera política y cultural que dividía el México civilizado de lo desconocido y de amenazas peligrosas. De este modo, los franceses se introdujeron al Valle de Misisipi realizando arreglos españoles en Texas; los intereses rusos y británicos en el noroeste del Pacífico causaron una serie de arreglos españoles en las Californias. Políticamente, los nuevos arreglos fueron vistos como zonas de parachoques protegiendo las riquezas de las minas de plata y pueblos hacia el Sur.

Las instituciones fronterizas españolas de Presidio, Misión, Pueblo y Real de Mina, fueron centralizando esencialmente los bienes propios controlados oficialmente por autoridades reales y eclesiásticas. En la era española uno de los conflictos centrales de la frontera, entre oficiales de la iglesia y los poderes seculares, era sobre el control de los indios. Este conflicto, junto con la inevitable influencia de nivel de vida fronteriza y la distancia de las regiones fronterizas de los centros de poder hechos por una sociedad que era mucho más democrática e individualista que cierta en el centro de México, hacía que de California a Texas, las autoridades eclesiásticas celosamente protegieran sus tierras de misiones y cargas.

Los ranchos de ganado que se desarrollaron durante el siglo XVI cambiaron dramáticamente la sociedad fronteriza, creando los elementos básicos de cultura norteña. Esta era una cultura en donde el hombre era juzgado por su manejo y destreza en el rodeo y por su habilidad de resistir todo tipo de privaciones y peligros. El vaquero, y despues el vaquero americano,nació en la frontera española-mexicana. Un espíritu de fuerte individualismo y una independencia tenaz eran elementos esenciales de la cultura del vaquero norteño. Por lo tanto, no es muy sorpendente que la mayoría de los guías revolucionarios de México hayan venido de las regiones fronterizas de cría de ganado y de minería. En la actualidad el Norte continúa esta tradición con explosiones esporádicas de independencia política.

Durante el siglo diecinueve la frontera mexicana continúo siendo un lugar de peligro e inseguridad. Guerrras constantes con el Apache, Yaqui, Mayo, Tarahumara y otros grupos indígenas, hacían el control administrativo fronterizo inseguro. Cuando los oficiales mexicanos pensaron en la región, pensaron en ella en términos españoles tradicionales como una zona de parachoques, que protege las ciudades más civilizadas de la Mesa Central. Como zona de parachoque fue expandida en 1848 cuando México la cedió a los Estados Unidos, esperando crear una tierra sin nombre entre el México propio y el Coloso del Norte. En la última parte del siglo XIX, Porfirio Díaz solieitó promover la emigración a esta zona para así poder construir una línea fronteriza defensiva en contra de los angloamericanos. A pesar de todo, la visión de invasión del Norte amenazaba los sueños de los líderes mexicanos. 
Estados Unidos invadió a México muchas veces antes del cambio de siglo. Las patrullas de guardianes tejanos y la Armada de Estados Unidos cruzaban la pobremente definida frontera persiguiendo indios y bandidos de ganado. Una invasión militar por el general John "Black Jack" Pershing en 1917, se notó debido a una larga serie de violaciones a la soberanía mexicana por parte de los Estados Unidos. El arreglo del controversial Chamizal en 1965 terminó una disputa que duró más de 100 años. El Chamizal tenía una importancia simbólica para los mexicanos como tangible evidencia de las ambiciones territoriales de Norteamérica. Su arreglo marcó una disminución de temores mexicanos acerca de violaciones de su territorio por "bárbaros" norteños, pero los temores ańtiguos eran difíciles de borrar. Ahora el enfoque se volvió a las penetraciones culturales de la civilización angloamericana en México.

En la imaginación de los mexicanos, la zona fronteriza, por ambos lados, y siendo los ocho Estados norteños mexicanos, es el área que se juzga como sujeta a influencias corruptivas de los Estados Unidos. Las ciudades fronterizas de Tijuana, Juárez, Nogales, Matamoros y Monterrey tienen los más altos standards de vida en México, sin embargo están consideradas como ciudades atrasadas culturalmente. Las élites en el centro de México consideran la frontera norteña como desarraigada. Los habitantes de la frontera mexicana son vistos como gente anormal influenciada por culturas angloamericanas. Al mismo tiempo, el lado americano de la frontera sigue siendo un área de misterio y oportunidad económica. La versión del siglo veinte de la Leyenda de las Siete Ciudades de Cíbola está relatada en las vecindades y barrios de las ciudades fronterizas acerca de las oportunidades de trabajo en Chicago, Denver, Dallas, Houston o Los Angeles.

Sin embargo, los mexicanos no están tan preocupados acerca de una invasión militar del Norte como lo están acerca de una cultural. Al regresar, las emigrantes mexicanos traen influencias americanas en música, vestido y, quizá lo más importante, en aspiraciones. Al mismo tiempo los mexicanos de la región fronteriza se sienten, como siempre lo han hecho, aislados y abandonados del centro. Aquellos que no son emigrantes están orgullosos de ser norteños y sienten que su contribución a la vida mexicana ha sido despreciada por el sur cosmopolitizado. Resienten interferencia del exterior en su autonomía local. La cultura rancbers es todavía más importante y los mitos del vaquero sierven como parte del cemento cultural. Sin embargo, paradójicamente, la mayoría de los norteños no son vaqueros sino inmigrantes urbanos nuevos, con muy poca identidad histórica con la región. La región fronteriza mexicana es un lugar de transición demográfica y cultural. De vital importancia económica a la nación, la región fronteriza está aún desarrollándose en su identidad social y cultural.

\section{Puntos de vista americanos}

Los angloamericanos primero entraron a la región fronteriza mexicana a principios de 1800 como cazadores de pieles y exploradores militares. Para ellos, esta región estaba al oeste y al sur de su civilización americana, 
por lo tanto, era conocida como el Suroeste. Desde el principio el Suroeste era visto como un lugar de oportunidad económica sin par. Los años derla tierra rica en oro ayudaron mucho para reforzar en la mentalidad americana, un "auge" imaginario de la región. Desde el punto de vista americano, esta prosperidad estaba peligrando por la existencia de varios grupos indígenas preindustrializados y mexicanos.

Uno de los temas centrales de la conquista americana de esta región tuvo que ver con la idea de aprovechamiento en su totalidad. La idea se desarrolló porque las razas nativas y mexicanas eran deficientes en el uso de recursos naturales de la región y por lo tanto deberían y se podrían desposeer para dar paso al progreso. Desde los tiempos de Stephen Austin hasta las luchas actuales de los indios nativos sobre los derechos de aguas, los angloamericanos se han enfocado constantemente en desarrollar lo físico oponiéndose a los recursos humanos del Suroeste. El desarrollo es una palabra clave. Para utilizar en su totalidad los recursos se volvió necesario construir miles de millas de ferrocarril, tener el control de tierras mexicanas (el Tratado Gatsen, las concesiones de tierras de California y México y los tratados de tierras de los indios), construir proyectos grandes de irrigación, introducir modernas tecnologías de minería y promover la inmigración de mano de obra barata (chinos, indúes y mexicanos nacionalizados). Desarrollo significa la reorganización de los patrones culturales existentes y los sistemas políticos a su vez.

Sin embargo, para los angloamericanos la región fronteriza no ha sido un lugar de peligro y amenaza primordial. Más bien es un lugar de oportunidades excepcionales para desarrollos capitalistas dependientes, en gran forma, en mano de obra barata y energía. El programa bracero de los años 1940 que duró hasta 1965 fue un atentado institucional para asegurar la prosperidad del Suroeste. La negociación con México respecto a los derechos del agua, destacó como el asunto de mayor importancia para el desarrollo de la región a través del siglo veinte. Un tratado internacional firmado en 1944 prometió asegurar el crecimiento continuo de los americanos.

La creación del Suroeste "dorado" ha tenido sus costos humanos, empezando por los méxicoamericanos e indios que obstruían el camino. La región fronteriza ha tenido, desde 1948, una reputación de desórdenes, el asilo o refugio para desesperados, contrabandistas y bandidos. La frontera parecía tener la ley en sus propias manos, un lugar en donde los únicos ciudadanos reconocidos eran la policía, los guardianes tejanos, la Armada y los oficiales de Migración. En Texas y Arizona la línea internacional tenía una historia sangrienta de conflictos entre oficiales angloamericanos y residentes mexicanos en los Estados Unidos. Violencia y refugios eran las más sobresalientes características de la región hasta el principio de la gran depresión en 1929.

Durante la era de prohibición y continuando hasta el presente, la región fronteriza adquirió una reputación de pobreza y vicio, quizá por su proximidad a los salones operados y adquiridos por americanos, burdeles, 
pistas de carreras y casinos en las ciudades fronterizas mexicanas. No inconsecuente a este despectivo punto de vista, es el hecho de que el lado americano de la frontera siempre ha sido poblado en su mayoría por americanos de ascendencia mexicana y emigrantes mexicanos recientes. Ambos grupos han sido históricamente vistos por angloamericanos como si fueran moralmente defectuosos. Aún hoy, se piensa que la región fronteriza es un lugar de exitación sensual y placeres ilícitos, siendo que en realidad, las industrias del pecado que se encuentran en las mayores áreas metropolitanas de los Estados Unidos están más dispuestas a la perversidad que en la mayoría de las ciudades fronterizas mexicanas o americanas.

Para los americanos la región fronteriza es considerada la mayoría de las veces en términos de "la línea", la frontera internacional y los asentamientos adyacentes mexicanos inmediatos a ella. Los americanos no están preocupados particularmente por la mexicanización de su lado de la línea. Un etnocentrismo cultural, y quizá el sentido de superioridad nacional prevalece. El american way of life, junto con sus oportunidades económicas, es asumido para permanecer intacto hasta la frontera.

\section{Divergencia y convergencia}

Obviamente las diferencias históricas entre los puntos de vista mexicanos y americanos acerca de la región fronteriza son complejos y, hasta cierto grado, paradójicos. Mientras que la mayoría de los mexicanos continúan viendo la zona fronteriza como una zona de parachoque de poca importancia para el "México real", la región ha jugado y continúa jugando un papel vital en la política mexicana, en su cultura y desarrollo económico. Los americanos continúan viendo la frontera como un lugar de oportunidades económicas excepcionales como evidencia de un crecimiento fenómeno de maquiladoras (plantas ensambladoras fronterizas) y un reciente interés en "el mercado mexicano". Al mismo tiempo, el punto de vista popular es que la frontera es una región de suma pobreza, desordenada y degradante.

Históricamente, para mexicanos y americanos, la frontera ha sido un lugar de conflicto y mezcla cultural. Pero ni los americanos ni los mexicanos parecen apreciar totalmente las diversidades históricas de las características tradicionales y culturales de la región fronteriza. No es, y nunca ha sido, una zona homgénea. Hay una tendencia perturbadora, entre los planeadores de pólizas, a ver la región como una sola entidad, lo cual no lo es. Las semitropicales Texas y Tamaulipas tienen historias muy diferentes que aquellas del estado desértico de Sonora. Las Californias están mundos aparte de estas otras dos regiones. La venerable Ciudad Juárez, fundada en el siglo XVII es totalmente diferente de Tijuana, una ciudad que fue incorporada en 1925. Similarmente, San Diego casi no es una ciudad fronteriza en el mismo sentido que El Paso.

Históricamente la cultura de la región fronteriza ha sido influenciada por factores comunes tales como aridez y la competencia por el agua, los problemas marginales económicos y políticos y los cambios demográficos 
éfectuados por las migraciones internas masivas. Desde luego que hay muchos problemas comunes compartidos por los estados fronterizos de Estados Unidos y México: pobreza rural y urbana, energía, contaminación, migración urbana y dependencia económica son sólo unos cuantos. Una discusión productiva de estos aspectos comunes, sin embargo, solo puede venir de un entendimiento firme de suposiciones históricas generadas acerca de la región. 